\title{
Angiographic Severity of Coronary Artery Disease among Patients with Non-ST Elevated Acute Coronary Syndrome having Fragmented-QRS in ECG
}

\author{
MD. ABU RAIHAN FERDOUS ${ }^{1}$, MRM MANDAL ${ }^{1}$, FAISAL IBN KABIR ${ }^{1}$, MD RASULAMIN ${ }^{1}$, SYED ALI AHSAN ${ }^{1}$, \\ SM EAR E MAHBUB ${ }^{1}$, AKM MOHIUDDIN BHUIYAN ${ }^{2}$, MD. MUKHLESUR RAHMAN ${ }^{1}$ \\ ${ }^{1}$ Department of Cardiology, Bangabandhu Sheikh Mujib Medical University, Shahbag, Dhaka, ${ }^{2}$ National Institute of \\ Ophthalmology and Hospital, Dhaka
}

Address for Correspondence: Dr. Md. Abu Raihan Ferdous, Department of Cardiology, Bangabandhu Sheikh Mujib Medical University, Shahbag, Dhaka.E mail - raihank57@gmail.com

\begin{abstract}
:
Fragmented QRS (f-QRS) complex in 12 lead ECG may develop in the background of acute coronary syndrome (ACS). This study was aimed to evaluate the angiographic severity of CAD among non-ST ACS patients having $f$-QRS in the ECG.This cross-sectional observational study was conducted in Cardiology department of BSMMU. Total 52 non-ST ACS patients who underwent invasive coronary angiography (CAG) were included in two groups according to presence or absence of $f$-QRS complex. 25 patients were included in $f$-QRS group and 27 in non-f-QRS group. After CAG, severity of CAD was assessed and compared by number of vessel involvement and degree of vessel stenosis. Patients' demographic parameters were same in both groups. Depending on the number of vessel involvement, it was found that among $f$-QRS patient group, highest percentage had triple vessel (32\%) followed by double vessel (28\%) and single vessel (24\%) disease and 16\% patient had normal or non-critical epicardial coronary arteries. Among non-f QRS group, highest percentage had normal or non-critical lesions (40.7\%) followed by double vessel (25.9\%), single vessel (22.2\%) and triple vessel disease (7.4\%). In conclusion, this study revealed that presence of $f-Q R S$ in ECG is associated with more severe form of $C A D$ and once the finding is observed, the particular patient should be targeted for aggressive management.
\end{abstract}

University Heart Journal 2020; 16(1): 28-32

Introduction:

Cardiovascular disease (CVD) is the number one cause of death worldwide, accounting for 17.9 million deaths in 2015. The age-standardized death from CVD has been increased in Bangladesh in comparison to statistics of $1990^{1}$. There is limited data about exact age and sex adjusted prevalence of CAD in Bangladesh but CAD prevalenceis between $1.85 \%$ and $3.4 \%$ in rural and $19.6 \%$ in an urban sample of working professionals ${ }^{2}$. Epidemiological data suggest that acute Non-ST elevated Myocardial Infarction (NSTEMI) occurs more frequently than STelevatedmyocardial infarction (STEMI) ${ }^{3}$. NSTEACS patients suffer more recurrent events and worse longterm outcomes ${ }^{4}$.

To identify this phenomenon until now Electrocardiography (ECG) is the most immediately accessible and widely used diagnostic tool. f-QRS complexes are novel electrocardiographic signals which reflect impaired ventricular depolarization due to heterogeneous electrical activation of ischemic and/or injured ventricular myocardium. f-QRS complexes on a 12lead resting ECG are defined as various RSR2 patterns
( $\geq 1 \mathrm{R} 2$ or notching of S wave or R wave) with or without Q waves lacking a typical bundle-branch block in 2 contiguous leads corresponding to a major coronary artery territory. Sometimes, f-QRS might be the only ECG marker of myocardial injury in patients with non-Q myocardial infarction and in patients with a resolved $Q$ wave s,6,7. $^{5}$.

Data regarding correlation between $\mathrm{f}-\mathrm{QRS}$ Complexes with the severity of CAD in patients with Non-ST ACS may play important role for future care of thesepatients. To date there is limited number of studies that specifically address fragmented QRS Complexes associated with severity of CAD and local data from Bangladesh is insufficient. Therefore, in view of the above scenario, the study was designed.

\section{Materials and Methods:}

This cross sectional observational study was done in the department of cardiology, University Cardiac Centre, Bangabandhu Sheikh Mujib Medical University, Dhaka, Bangladesh from October 2017 to March 2018. Inclusion criteria were cases of non-ST elevated ACS patients (Unstable angina, NSTEMI) with f-QRS ornon-fQRS 
complexes who underwent coronary angiography and who were $>18$ years of age and had given informed written consent.

Exclusion criteria were Age $<18$ years, left and right bundle branch block (complete or incomplete), Permanent atrial fibrillation, Ventricular paced rhythm, implanted cardioverter-defibrillator (ICD), Left ventricular hypertrophy, WPW-syndrome, Cardiomyopathy, Myocarditis, Congenital heart disease, Coronary artery bypass surgery (CABG), unwilling to perform coronary angiogram, not given informedconsent.

Total 52 patients were included in this study. Initially, patients were evaluated by history, clinical examination, ECG and Troponin-I. Demographic data like age, sex etc. were recorded. Risk factors of CAD including hypertension, diabetes, dyslipidemia, smoking and family history of CAD were noted. Study subjects were grouped into f-QRS group (25 cases) and non-fQRS group (27 cases) according to presence or absence of $\mathrm{f}-\mathrm{QRS}$ complex.

Finally, diagnostic coronary angiography was performed via either the transfemoral or trans-radial approach by expert interventional cardiologist using standard techniques. Angiographic findings including dominance (left, right or co-dominant), numbers and types of coronary vessel involved, including left main (LM), left anterior descending (LAD) artery, left circumflex (LCX), ramus intermedius (RI) and right coronary artery (RCA) were retrieved. The extent of coronary artery disease (CAD) was assessed in respect of the number of diseased vessels i.e. single, double or triple vessel disease and grading of stenosis was assessed by percentage of coronary arterial lumen occluded.

\section{Result:}

The age of the study population ranges from $32-77$ years. The mean age of $\mathrm{f}-\mathrm{QRS}$ and non-fQRS groups were
$53.28 \pm 12.57$ and $55.70 \pm 11.66$ respectively $(\mathrm{p}=0.47)$. Table-I shows the age distribution of the study subjects. In $\mathrm{f}-\mathrm{QRS}$ group 20 patients $(80 \%)$ were male and 5 patients $(20 \%)$ were female and in non f-QRS group 20 patients $(74.07 \%)$ were male and 7 were female $(25.93 \%)$. No significant association was found between two groups in relation to $\operatorname{sex}(p=>0.5)$. $p$ value derived from Chi-square test.

Risk factors analysis reveals that highest percentage had history of hypertension (56\%), followed in decreasing order by DM (52\%), dyslipidemia (44\%), smoking (32\%) and family history of CAD (20\%) in the f-QRS group. Smoking, hypertension, diabetes, dyslipidemia and family H/O CAD was higheramong f-QRS group than non-fQRS group. It was observed that only diabetes and dyslipidemia were significantly $(\mathrm{p}<0.05)$ higher in $\mathrm{fQRS}$ group than non-fQRS group patients (Table-II).

Comparison between $\mathrm{f}-\mathrm{QRS}$ and non-fQRS group according to number of vessel involvement reveals that patients who had f-QRS majority had triple vessel disease $(32 \%)$, followed in decreasing order by double vessel disease $(28 \%)$, single vessel disease $(24 \%)$ and normal vessel or non-critical lesion (16\%). Among patients who had non-fQRS majority had normal vessel or non-crictical lesion $(40.7 \%)$, followed in decreasing order by double vessel disease (25.9\%), single vessel disease (25.9\%) and triple vessel disease (7.4\%). f-QRS group had significantly higher proportion of triple vessel disease $(p=0.02)$ and non-fQRS group had significantly higher proportion of normal vessel or vessel with non-critical lesion $(p=0.04)$.

Degree of stenosis was compared in subjects who had single vessel disease only. 6 patients in each group had single vessel disease (SVD).Among them most patients (50\%) of f-QRS group had 70 to $<90 \%$ stenosis whereas most patients (50\%) of non-fQRS group had 50 to $<70 \%$ stenosis. But these findings were not significant statistically.

Table-I

Age distribution of study subjects

\begin{tabular}{|c|c|c|c|c|c|c|c|}
\hline \multirow[t]{2}{*}{ Age in years } & \multicolumn{2}{|c|}{$\mathrm{f}-\mathrm{QRS}$ group $(\mathrm{n}=25)$} & \multicolumn{2}{|c|}{ Non-fQRS(n=27) } & \multicolumn{2}{|c|}{$\operatorname{Total}(\mathrm{n}=52)$} & \multirow[t]{2}{*}{$p$ value } \\
\hline & Number & $\%$ & Number & $\%$ & Number & $\%$ & \\
\hline $31-40$ & 6 & 24 & 2 & 7.4 & 8 & 15.4 & $0.405^{\mathrm{ns}}$ \\
\hline $41-50$ & 6 & 24 & 10 & 37 & 16 & 30.8 & \\
\hline $51-60$ & 7 & 28 & 6 & 22.2 & 13 & 25.0 & \\
\hline$>60$ & 6 & 24 & 6 & 33.3 & 15 & 28.8 & \\
\hline Mean \pm SD & \multicolumn{2}{|c|}{$53.28 \pm 12.57$} & \multicolumn{2}{|c|}{$55.70 \pm 11.66$} & \multicolumn{2}{|c|}{$54.53 \pm 12.05$} & $0.476^{\mathrm{ns}}$ \\
\hline Range & \multicolumn{2}{|c|}{$35-77$} & \multicolumn{2}{|c|}{$32-77$} & \multicolumn{2}{|c|}{$32-77$} & \\
\hline
\end{tabular}

$p$ value reached from unpaired student $t$ test and Chi-square test. ns $=$ Not Significant $(\mathrm{p}>0.05)$ 
Table-II

Risk factors analysis of study subjects

\begin{tabular}{|c|c|c|c|c|c|c|}
\hline \multirow[t]{2}{*}{ Risk factors } & & \multicolumn{2}{|c|}{ f-QRS group $(n=25)$} & \multicolumn{2}{|c|}{ Non-fQRS(n=27) } & \multirow[t]{2}{*}{$p$ value } \\
\hline & & Number & $\%$ & Number & $\%$ & \\
\hline \multicolumn{7}{|l|}{ Smoking } \\
\hline & Yes & 8 & 32 & 7 & 25.9 & $0.63^{\mathrm{ns}}$ \\
\hline & No & 17 & 68 & 20 & 74.1 & \\
\hline \multicolumn{7}{|c|}{ Hypertension } \\
\hline & Yes & 14 & 56 & 15 & 55.6 & $0.97^{\mathrm{ns}}$ \\
\hline & No & 11 & 44 & 12 & 44.4 & \\
\hline \multicolumn{7}{|c|}{ Diabetes Mellitus } \\
\hline & Yes & 13 & 52 & 6 & 22.2 & $0.03^{\mathrm{s}}$ \\
\hline & No & 12 & 48 & 21 & 77.8 & \\
\hline \multicolumn{7}{|c|}{ Dyslipidaemia } \\
\hline & Yes & 11 & 44 & 5 & 18.5 & $0.04^{\mathrm{s}}$ \\
\hline & No & 14 & 56 & 22 & 81.5 & \\
\hline \multicolumn{7}{|c|}{ Family H/O of CAD } \\
\hline & Yes & 5 & 20 & 3 & 11.1 & $0.31^{\mathrm{ns}}$ \\
\hline & No & 20 & 80 & 24 & 88.9 & \\
\hline
\end{tabular}

$p$ value reached from Chi-Square tests $=$ Significant $(\mathrm{p}<0.05)$, ns $=$ Not Significant $(\mathrm{p}>0.05)$

Table-III

Comparison of number of vessel involvement between $f-Q R S$ and non- $f Q R S$ group $(n=52)$

\begin{tabular}{|c|c|c|c|c|c|}
\hline \multirow[t]{2}{*}{ Vessel number } & \multicolumn{2}{|c|}{ f-QRS group $(n=25)$} & \multicolumn{2}{|c|}{ Non-fQRS(n=27) } & \multirow[t]{2}{*}{$p$ value } \\
\hline & Number & $\%$ & Number & $\%$ & \\
\hline 0 & 4 & 16 & 11 & 40.7 & $0.04^{\mathrm{s}}$ \\
\hline 1 & 6 & 24 & 6 & 22.2 & $0.87^{\mathrm{ns}}$ \\
\hline 2 & 7 & 28 & 7 & 25.9 & $0.86^{\mathrm{ns}}$ \\
\hline 3 & 8 & 32 & 2 & 7.4 & $0.02^{\mathrm{s}}$ \\
\hline
\end{tabular}

$p$ value reached from Chi-Square tests $=$ Significant $(\mathrm{p}<0.05)$, ns $=$ Not Significant $(\mathrm{p}>0.05)$

Table-IV

Comparison of the study subjects according to degree of stenosis of involved Coronary Artery

(For single vessel disease only) $(n=12)$

\begin{tabular}{lcccccc}
\hline Degree of stenosis & \multicolumn{2}{c}{$\mathrm{f}-\mathrm{QRS}$ group $(\mathrm{n}=25)$} & & \multicolumn{2}{c}{ Non-fQRS(n=27) } & \\
\cline { 2 - 3 } (in percentage) & Number & $\%$ & & Number & $\%$ value \\
\hline $\mathbf{5 0}$ to $<\mathbf{7 0}$ & 2 & 33.3 & & 3 & 50.0 & $0.55^{\text {ns }}$ \\
$\mathbf{7 0}$ to $<\mathbf{9 0}$ & 3 & 50.0 & & 2 & 33.3 & $0.55^{\text {ns }}$ \\
$\mathbf{9 0}$ to d"100 & 1 & 16.7 & & 1 & 16.7 & $1.00^{\text {ns }}$ \\
\hline
\end{tabular}

$p$ value reached from Chi-Square test $\mathrm{s}=$ Significant $(\mathrm{p}<0.05), \mathrm{ns}=$ Not Significant $(\mathrm{p}>0.05)$

Univariate logistic regression analysis was done to see the effects of determinants of severe CAD. Here severe CAD was defined by the presence of triple vessel disease. Age $>50$ years, DM and presence of $f-Q R S$ showed significant independent association with severe coronary artery disease $(\mathrm{p}<0.05)$. Other variables including male sex, smoking, hypertension, dyslipidaemia and family history of CAD also showed non-significant association with severe CAD.Multivariate logistic regression analysis was done to see the overall combined effects of determinants 
of severe CAD. Only Age $>50$ years was found to retain the significance as an independent risk factor associated with severe coronary artery disease $(\mathrm{p}<0.05)$.

\section{Discussion:}

A total of 52 patients of non-STACS admitted in cardiology department of BSMMU during the study period were evaluated consideringthe inclusion and exclusion criteria.

Patients were divided into two groups on the basis of presence or absence of $\mathrm{f}-\mathrm{QRS}$ complex in 12 lead ECG. 25 patients were included in $\mathrm{f}-\mathrm{QRS}$ group and 27 patients were included in non-f-QRS group. The mean age of $\mathrm{f}-\mathrm{QRS}$ patients was $53.28 \pm 12.57$ years and the mean age of nonfQRS patients was $55.70 \pm 11.66$ years.Bekler A, et al ${ }^{8}$ (2015) showed relationship between fQRS complexes and Syntax and Gensini scores in patients with acute coronary syndrome.

A total of 302 patients with acute coronarysyndrome were included and the mean age for fQRS and non-fQRS were 65 and 63 years respectively. In another study regarding the predictive value of fQRS complex in ACS patients, the mean age of study population was $57.7 \pm 12.8$ years $^{9}$. Risk factors analysis revealed that highest percentage of the patients had history ofhypertension. Among f-QRS group, 14 (56\%)patients had hypertension and it was in $15(55.6 \%)$ among non-fQRS group. DM was the second commonest risk factor after hypertension in f-QRS group.13 (52\%)patients were diabetic in f-QRS group whereas 6 $(22.2 \%)$ patients were diabetic in non-fQRS group.Other risk factors were also greater among patients having fQRS complexes.According to Stavileci et al ${ }^{10}$, the percentage of hypertension was very close in both groups as found in this study but diabetes mellitus was found in $35 \%$ cases of $\mathrm{f}-\mathrm{QRS}$ group and smoking history was higher $(>60 \%)$ for both the groups than this study.

In this study, triple vessel disease was significantly associated with fQRS group $(\mathrm{p}=0.02)$. Total $8(32 \%)$ patients of this group had triple vessel disease compared to only 2 (7.4\%) patients of non-fQRS group.Frequency of single and double vessel diseases were slightly higher in fQRS group but without statistical significance. Normal or noncritical lesions on coronary angiographywere found in 4 (16\%) and 11 (40.7\%) patients of f-QRS and non-fQRS group respectively which was significant $(\mathrm{p}=0.04)$.

Patients in $\mathrm{fQRS}$ group showed more severe degree of coronary occlusion. Severity of stenosis was compared among SVD patients. Most of them in f-QRS group had 70 to $<90 \%$ stenosis $(50 \%$ vs. $33.3 \%$; $=0.55)$ but this difference was insignificant. The association of $\mathrm{f}-\mathrm{QRS}$ and severe form ofcoronary artery disease may be due to increased jeopardized ischaemic myocardium that may in turn alsocontribute to non-homogenous conduction inthe myocardium ${ }^{11}$.Fragmentations were relatedto presence of stunned myocardiumthat may resolve in the course of disease and in other situations cannot be resolved due to presence of myocardial scar ${ }^{12}$.

\section{Limitations of the study:}

It was a single centered study. Result of the study might be influenced by relatively smaller sample size. For sampling, randomization could not be done.

\section{Conclusion:}

This study reveals that non-ST ACS patients with f-QRS complexes have severe form of coronary artery disease and it was evident by more frequent presence of triple vessel disease among f-QRS group.

\section{References:}

1. Roth, G. A., Johnson, C., Abajobir, A., Abd-Allah, F., Abera, S. F., Abyu, G. et al, 'Global, Regional, and National Burden of Cardiovascular Diseases for 10 Causes, 1990 to 2015'. Journal of the American College of Cardiology, 2017; 70(1):1-25.

2. Islam, A., K. and Majumder, A. A. 'Coronary artery disease in Bangladesh: a review', Indian Heart J. Elsevier, 2013;65(4), 424-435.

3. McManus, D., Gore, J., Yarzebski, J., Spencer, F., Lessard, D. and Goldberg, R. 'Recent Trends in the Incidence, Treatment, and Outcomes of Patients with ST and Non-ST-Segment Acute Myocardial Infarction', Am J Med, 2011;124(1):40-47.

4. Kumar, A. and Cannon, C. P. 'Acute coronary syndromes: diagnosis and management, part I', Mayo Clinic proceedings, 2009;84(10):917-38.

5. Cetin, M., Kocaman, S. A., Kiris, T., Erdogan, T., Canga, A., Durakoglugil, M. E. et al. 'Absence and Resolution of Fragmented QRS Predict Reversible Myocardial Ischemia With Higher Probability of ST Segment Resolution in Patients With ST Segment Elevation Myocardial Infarction', Korean Circulation Journal, 2012;42:674-683.

6. Das, M.K., Khan, B., Jacob, S., Kumar, A. and Mahenthiran, J. 'Significance of a fragmented QRS complex vs a Q wave in patients with coronary artery disease', Circulation, 2006;113:2495-501.

7. Take, Y. and Morita, H. 'Fragmented QRS: What is the meaning?', Indian Pacing and Electrophysiology Journal, 2012;12(5):213-225.

8. Bekler, A., Baructu, A., Tenekecioglu, E., Altun, B., Gazi, E., Temiz, A., Kirilmaz, B., Ozkan, M. T. A. and Yener, A. U. 'The relationship between fragmented QRS complexes and SYNTAX and Gensini scores in patients with acute coronary syndrome', KardiologiaPolska, 2015;73(4):246-254.

9. Akbarzadeh, F., Pourafkari, L., Ghaffari, S., Hashemi, M. and Sadeghi-Bazargani, H. 'Predictive value of the fragmented 
QRS complex in 6-month mortality and morbidity following acute coronary syndrome', International Journal of General Medicine , 2013;6:399-404.

10. Stavileci, B., Cimci, M., Ikitimur, B., Barman, H. A., Ozcan, S., EsraAtaoglu, E., M.D. and Enar, R. 'Significance and Usefulness of Narrow Fragmented QRS Complex on 12-Lead Electrocardiogram in Acute ST-Segment Elevation Myocardial Infarction for Prediction of Early Mortality and Morbidity', Ann Noninvasive Electrocardiol, 2014;19(4):338-344.
11. Das, M. K. and Zipes, D. P. 'Fragmented QRS : A predictor of mortality and sudden cardiac death', Hearth Rhythm, 2009;6(3):S8-S14.

12. KocamanSinanAltan et al. 'The importance of fragmented QRS complexes in prediction of myocardial infarction and reperfusion parameters in patients undergoing primary percutaneous coronary intervention', Arch Turk SocCardiol, 2012;40(3):213-22. 